\title{
LA DOCTRINA DE LA SUSTITUCIÓN CONSTITUCIONAL EN COLOMBIA: UNA APROXIMACIÓN A LA JURISPRUDENCIA CONSTITUCIONAL*
}

\author{
The doctrine of constitutional substitution in Colombia: \\ an approach to constitutional Jurisprudence
}

\section{Milton César Jiménez Ramírez}

Abogado, Universidad de Caldas

Especialista en Derecho Constitucional, Universidad Nacional de Colombia;

Magister en Derecho Público, Universidad Externado de Colombia;

Doctor en Derecho, Universidad Carlos III de Madrid; docente investigador

del Departamento de Jurídicas de la Universidad de Caldas

\section{Paulo Bernardo Arboleda Ramírez}

Abogado, Universidad de Medellín; Especialista en Derecho Público, Universidad Externado de Colombia; y, Magíster en Derecho, Universidad de Medellín; docente del Departamento de Jurídicas de la Universidad de Caldas

http://dx.doi.org/10.18543/ed-69(2)-2021pp123-148

Recibido: 29.07.2021

Aceptado: 13.12 .2021

\section{Resumen}

La sustitución implica el reemplazo o la limitación excesiva de un elemento definitorio o estructural de la constitución en el marco de la reforma constitucional. Se ha establecido como una metodología judicial para discernir si una reforma constitucional puede ser inconstitucional. Este estudio hace una aproximación al concepto de la

* Este trabajo de investigación es producto de una estrategia de cohesión investigativa en el marco del proyecto de investigación: «Derecho y Ciencia» y de la política de producción investigativa del Centro de Investigaciones Jurídicas, Políticas y Sociales (CIS). 
sustitución de la constitución en Colombia, instaurado a través de la jurisprudencia de la Corte Constitucional, con el fin de determinar sus principales fundamentos y requisitos de aplicación. Esta investigación se divide en dos partes: i) La identificación de las principales razones utilizadas por el Tribunal constitucional para fundar esta doctrina, especialmente el concepto de defensa de la supremacía constitucional y el poder constituyente; ii) evidenciar la evolución de la doctrina desde su surgimiento en el 2003 hasta el 2019; finalmente, se presentarán las conclusiones relacionadas con la posibilidad que la sustitución se convierta en una extralimitación judicial. Esta investigación utilizó el método bibliográfico o documental con enfoque hermenéutico y analítico, específicamente para la identificación y estudio de la jurisprudencia constitucional.

\title{
Palabras clave
}

Poder constituyente, Reforma constitucional, Supremacía constitucional, Sustitución constitucional.

\begin{abstract}
Substitution implies the replacement or excessive limitation of a defining or structural element of the constitution within the framework of the constitutional reform. It has been established as a judicial methodology to discern whether a constitutional reform may be unconstitutional. This study makes an approach to the concept of the replacement of the constitution in Colombia, established through the jurisprudence of the Constitutional Court, in order to determine its main foundations and application requirements. This investigation is divided into two parts: i) The identification of the main reasons used by the Constitutional Court to found this doctrine, especially the concept of defense of constitutional supremacy and constituent power; and ii) demonstrate the evolution of the doctrine from its emergence in 2003 to 2019. Finally, the conclusions related to the possibility that the substitution could become a judicial overreach will be presented. This research used the bibliographic or documentary method with a hermeneutical and analytical approach, specifically for the identification and study of Constitutional Jurisprudence.
\end{abstract}

\section{Keywords}

Constituent Power, Constitutional Reform, Constitutional Supremacy, Constitutional Substitution. 
SUMARIO: I. INTRODUCCIÓN. II. SUPREMACÍA CONSTITUCIONAL Y PODER CONSTITUYENTE: FUNDAMENTOS DE LA DOCTRINA DE LA SUSTITUCión De La CONSTITUCión. 1. Supremacía constitucional. 2. Poder Constituyente. III. DoCTRINA DE LA SUSTITUCIÓN EN EL RÉGIMEN JURÍDICO DE PAZ. IV. CONCLUSIONES. V. REFERENCIAS BIBLIOGRÁFICAS.

\section{INTRODUCCIÓN}

La Corte Constitucional se erige como máxima guardiana de la integridad de la Constitución Política de 1991 y, en consecuencia, desde 2003 ha realizado interpretaciones en sus sentencias sobre los artículos constitucionales que establecen los mecanismos de reforma de la Constitución; es así como esta Alta Corte ha desarrollado la doctrina de la sustitución constitucional para definir los límites de competencia del poder constituyente derivado -Función legislativa-, frente a la posibilidad de éste de cambiar ejes esenciales o contenidos axiológicos fundantes del ordenamiento jurídico colombiano. Este estudio hace una aproximación al concepto de la sustitución de la constitución en Colombia, instaurado a través de la jurisprudencia de la Corte Constitucional, con el fin de determinar sus principales fundamentos y requisitos de aplicación, especialmente para discernir si una reforma constitucional puede ser inconstitucional.

La Constitución Política de 1991 fue clara y expresa al manifestar en su artículo 241 que la Corte Constitucional tiene la facultad de realizar la revisión constitucional de los actos reformatorios de la Constitución, solamente por vicios de forma o procedimentales. Desde 1992 hubo consenso jurisprudencial y doctrinal, y la Corte invocando los "estrictos y precisos términos" del artículo 241, no realizaba ninguna revisión material o competencial de los actos legislativos. No obstante, en la Sentencia C-551 de 2003 con ponencia de Eduardo Montealegre se dijo que "aunque la constitución no tiene cláusulas pétreas, ni principios intangibles de manera expresa, las reglas de competencia impiden que la constitución sea sustituida por otra diferente”. La Corte expresa que el control constitucional sobre las reformas constitucionales "recae entonces sobre el procedimiento de reforma y no sobre el contenido material del acto reformatorio".

Sin embargo, la Corte matizó dicho control a través de la explicación de lo que se debe entender por vicio de forma o procedimental ${ }^{1}$. Al respecto,

${ }^{1}$ Sobre este poder de reforma se encuentra la Corte Constitucional de Colombia; entidad judicial encargada de velar por la integridad y la supremacía de la constitución en los términos de los artículos 241 al 244 de la Constitución Política. En consecuencia, la Corte Constitucional, según el artículo 241, numeral 2, tiene entre sus funciones estudiar la 
estableció que el vicio de forma o de procedimiento contiene dos tipos de defectos que son posibles de identificar sin tener que confrontar el contenido de la ley con la norma superior: Vicios de trámite o relativos al curso del acto reformatorio; y vicios de competencia para emitir determinados contenidos constitucionales. Por lo tanto, con dicho argumento, la Corte justifica que el control competencial, también es un control formal o de procedimiento.

La Corte interpreta que el poder de reforma es un poder constituyente derivado, lo que indica que a través de una reforma no se podrá sustituir la constitución, ya que el único que estará facultado o tiene la competencia para hacerlo será el constituyente primario. Ello significa que la tesis de sustitución surge como un límite al poder de reforma; en consecuencia, se estará ante una sustitución y no una reforma, cuando el acto reformatorio afecta la identidad de la constitución, modificando los principios o ejes axiales o definitorios de la constitución.

Dadas las cosas, esta investigación se dividen en dos partes: i) La identificación de las principales razones utilizadas por el Tribunal constitucional para fundar esta doctrina, especialmente el concepto de defensa de la supremacía constitucional y el poder constituyente; ii) evidenciar la evolución de la doctrina desde su surgimiento en el 2003 hasta el 2019; finalmente, se presentarán las conclusiones relacionadas con la posibilidad que la sustitución se convierta en una extralimitación judicial.

\section{SUPREMACÍA CONSTITUCIONAL Y PODER CONSTITUYENTE: FUNDAMENTOS DE LA DOCTRINA DE LA SUSTITUCIÓN DE LA CONSTITUCIÓN}

La Corte Constitucional, desde 1996, inició un trabajo jurisprudencial en torno a la reforma de la Constitución Política de 1991 (Sierra, 1998), desde la comprensión del principio de supremacía constitucional ${ }^{2}$. En tal sentido, la Corte Constitucional señala que el sistema normativo está jerarquizado para permitir unidad, coherencia y armonía entre las normas jurídicas, de manera que exista un orden axiológico y normativo. Entonces, la jerarquía de las normas jurídicas se configura en torno a la Constitución Política de 1991 en lo más alto del

constitucionalidad de las normas jurídicas solo por vicios de forma con anterioridad al pronunciamiento popular, sobre la constitucionalidad de la convocatoria a un referendo o a una Asamblea Constituyente para reformar la constitución. Se entiende por este tipo de vicios aquellos que están constituidos por todas las anomalías en que se incurre durante el trámite o proceso legislativo, ya sea por la omisión o quebrantamiento de cualquiera de los requisitos impuestos por el orden jurídico al proceso de formación y aprobación de las leyes, los que afectan su eficacia y validez.

2 Véase: Sentencias: C-037 de 1996, C-037 de 2000, C-1290 de 2001, C-207 de 2003, T-688 de 2003 y C-398 de 2006. 
ordenamiento jurídico, siendo ésta la fuente de validez de las demás normas jurídicas (Hesse, 1963; Kelsen, 1995). Así, las normas jurídicas de inferior categoría, deben ser coherentes e imputar con las superiores, y desarrollarlas o al menos no contradecirlas. Estas exigencias garantizan la coherencia interna del sistema jurídico, el cual está regido por un sistema axiológico que promueve la racionalidad del ordenamiento (Corte Constitucional, Sentencia C-037 de 2000).

De ahí la importancia del principio de supremacía constitucional que soporta a los principios esenciales de la constitución, entendiéndose por estos como aquellos fundamentos axiológicos esenciales en un determinado ordenamiento jurídico. En este orden de ideas, la Corte Constitucional desarrolló la teoría de la sustitución de la constitución, la cual consiste en la existencia de principios estructurales; esto con la finalidad de no permitir el cambio en la esencia de la constitución por parte del poder constituyente derivado - Congreso de la República- Sobre este asunto, la Alta Corporación, en Sentencia C-551 de 2003, manifestó que solo procede la sustitución de la constitución por Asamblea Nacional Constituyente, a través de la cual el pueblo concede la facultad de expedir una nueva constitución e instituir una opuesta o contraria a la vigente; posibilidad expresamente permitida en el artículo 376 de la Carta.

\section{Supremacía constitucional}

La supremacía de la constitución representa una garantía de los diseños constitucionales modernos pues su objetivo era no solo establecer a la constitución como una norma fundamental y prioritaria, sino como un instrumento del control del poder. Por ello, la supremacía de la Constitución (Guastini, 2010). es un freno a los intentos del poder público y de cualquier poder de desconocer el deber ser y las decisiones políticas sociales y económicas dispuestas por el constituyente. La supremacía asegura la vigencia de los mandatos políticos y especialmente de los axiológicos. Una defensa de la supremacía representa una carta necesaria para la gestión judicial, y una tarea justificativa de la existencia de la garantía jurisdiccional de la constitución. A la par, esa garantía jurisdiccional encarnada en el tribunal constitucional impone restricciones a la función legislativa y a las opciones del constituyente derivado, o también llamado poder de reforma de la constitución. Tales restricciones le otorgan el papel de legislador negativo cuando controla la constitucionalidad de las leyes frente a la constitución, pudiendo declararlas inconstitucionales y retirarlas del ordenamiento jurídico (Kelsen, 1995); pero también lo convierte en un constituyente negativo ${ }^{3}$ cuando para garantizarla primacía, la fuerza normativa y la

${ }^{3}$ La aplicación de la supremacía de la constitución en el control de constitucionalidad puede verse soportado en la Sentencia C-054/16, al efecto: "Ante comprensiones diferentes de una misma disposición el intérprete debe escoger una de ellas para ser aplicada en 
supremacía de la constitución, debe vigilar que el constituyente derivado, bien el legislador a través del acto legislativo, o cuando convoca al pueblo a un referendo o a la elección de una asamblea constituyente reformatoria, no respeta los procedimientos dispuestos para la reforma constitucional o pretende suplantar el lugar y las facultades del poder constituyente originario.

Dadas las cosas, la supremacía de la constitución es un fundamento trascendental para la implementación de la doctrina de la sustitución de la constitución pues tratándose de constituciones rígidas y flexibles (Ferrajoli, 2014), estas puede ser objeto de cambios conforme a las coyunturas políticas, sociales y económicas, y conforme a estos momentos, más allá de lo límites jurídicos, evadir, eludir o desconocer las decisiones fundamentales que establecieron la estructura básica de la constitución, lo que implicaría reducir la constitución, menguar sus consagraciones básicas tanto en la estructura, en su identidad como en los derechos y principios que consagra, cuando esta decisión requiere la presencia de un procedimiento democrático incluyente, deliberativo y políticamente trascendental, capaza de marcar la historia institucional de un Estado como es una asamblea constituyente total. En otras palabras, la presencia del poder constituyente originario. Mientras no se respete este procedimiento el cual garantiza la supremacía constitucional, la tarea del tribunal constitucional será requerir el respeto a estas decisiones fundamentales, particularmente salvaguardando su vigencia, pero sin caer en la creación jurisprudencial y material de cláusulas pétreas.

\section{Poder Constituyente}

La Constitución Política de Colombia de 1991 se deificó de tal manera que la concepción de Cartas de Batalla (Valencia, 2010) se dejó atrás hasta convertirse en un manual deontológico. La relatividad de la aplicación de sus cláusulas y la interpretación del Tribunal Constitucional matiza la reevaluación de las fuentes del derecho, al igual que las competencias que son asignadas desde el

casos concretos. Sin embargo, si esta tarea es asumida en el marco del control de constitucionalidad, el parámetro de escogencia es la vigencia de la Constitución, por lo que la Corte, a partir de la función directiva de la Carta Política, define qué comprensiones de las normas resultan compatibles con la supremacía constitucional, proscribiendo aquellas que no cumplan con esa condición. A su vez, en caso que ninguna de ellas esté conforme a la Constitución, se infiere la inexequibilidad del enunciado normativo y su consecuente expulsión del orden jurídico. En otras palabras, conforme a la función directiva de la supremacía constitucional, la armonía con la Carta Política opera como árbitro entre dichas interpretaciones jurídicas divergentes, otorgándose con ello no solo plena eficacia de dicho principio, sino también seguridad jurídica, la racionalidad y la razonabilidad al orden jurídico en su conjunto (Corte Constitucional, Sentencia C-054 de 2016). 
poder originario ${ }^{4}$. La Constitución de 1991 es una constitución parcialmente rígida, en razón a quienes pueden instaurar el proceso de la reforma.

Sobre el constituyente originario, es importante mencionar que la forma de gobierno democrática, en si misma genera o diseña lo que será la democracia del futuro ${ }^{5}$. El poder constituyente originario es un órgano de representación popular y nacional, cuyo fin está centrado en definir las leyes fundamentales o decisiones político estructurales dentro del Estado y para la determinación de sus fines con controles y protección de los ciudadanos. La tarea de la Asamblea Constituyente total se materializa en decisiones tales como: La organización del Estado, la delimitación y uso de su territorito, la consagración y garantía de los derechos fundamentales, el control del poder, y la democracia (Hesse, 1963). Así pues, se habla entonces de un constitucionalismo moderno en el que la constitución garantiza los fundamentos mínimos para la existencia de una democracia ${ }^{6}$. Este momento histórico en cada sociedad, puede ser asimilado en el pensamiento de Ackerman (2011), como un ejercicio excelso de la política constitucional que la hace diferente del ejercicio común de la misma.

En tal sentido, se presupone que el órgano promotor de la constitución está política y jurídicamente legitimado, debido a su elección popular y por detentar un encargo relevante, como la creación de una constitución con cláusula democrática ${ }^{7}$. La Asamblea constituyente es el momento de mayor expresión de la voluntad política ${ }^{8}$, suficiente para fundamentar que se respete

${ }^{4}$ En la sentencia C-544 de 1992 la Corte sostuvo que el poder constituyente es el pueblo, en el cual reside la soberanía, entendiéndose como el poder político fundacional permanente, sin límites y sin control jurisdiccional. En este orden de ideas, el poder del pueblo encuentra validez en la propia voluntad política de la sociedad. Al respecto: "El acto de elaboración y de promulgación de la nueva Carta Política de 1991, es el resultado de la combinación armónica de distintos elementos y de varios procesos de orden político y jurídico que, aun cuando conforman un episodio sui generis en la historia constitucional colombiana y sin alterar la normalidad social ni económica de la Nación, permitieron la expresión originaria del poder Constituyente, dentro de cauces institucionales diseñados específicamente, con el fin de superar la crisis que presentaba el modelo de organización del Estado ante los embates del crimen organizado y ante la creciente deslegitimación de las reglas y de los eventos de la democracia representativa vigente" (Corte Constitucional, Sentencia C-544 de 1992).

5 Véase: Touraine, A. (2000). ¿Qué es la Democracia? (Trad. H. Pons). México: Fondo de Cultura Económica. Bobbio, N. (1992). El futuro de la democracia. (Trad. J. Fernández Santillán). Bogotá, Colombia: Fondo de Cultura Económica.

${ }^{6}$ Véase: Gargarella, R. (2004). Constitución y democracia. En S. Albanese, A. Dalla, R. Gargarella, A. Hernández y D. Sabsay (orgs.), Derecho Constitucional (págs. 69-85). Buenos Aires: Editorial Universidad.

7 Véase: Arboleda, P. y Jiménez, M. (2016). Una aproximación a la filosofía política de la cláusula democrática en la Constitución de 1991. Revista Filosofía UIS, (15) 19-46.

${ }^{8}$ Véase: Schmitt, C. (2009). El Concepto de lo Político. Madrid: Alianza Editorial. 
la norma constitucional y el proyecto social estipulado, especialmente el de la participación democrática.

De esta manera, se entiende que la constitución surge de un momento democrático, salvaguardado bajo la garantía jurídica y política de la supremacía y garantía jurisdiccional. Sin embargo, no puede desconocerse que la fuerza de la democracia podría dejar sin efecto o reformar indefinidamente la Constitución' ${ }^{9}$. La democracia constitucional impone respeto a la racionalidad de los procedimientos como control al poder, a las mayorías y al poder político y social; asimismo, dispone que toda decisión sea también razonable por su respeto a los principios y derechos constitucionales. Por esta razón, si bien en una democracia constitucional es posible la reforma persistente e incluso la existencia de un constitucionalismo abusivo que trate de desplazar el deber ser constitucional, las decisiones esenciales de ese momento constituyente deben persistir hasta no ser nuevamente consideradas por un nuevo poder constituyente originario. Así la vida de una constitución puede implicar la presencia del poder constituyente en dos momentos:

i) El poder constituyente derivado como aquella posibilidad de reinterpretar los mandatos constitucionales, corregir, complementar, enmendar e incluso optimizar le diseño constitucional. La misión del constituyente derivado es movilizarse bajo la democracia constitucional, responder a las distintas generaciones y a los diferentes momentos políticos e históricos, de ejercer el derecho a la revisión de la constitución, tratando que la reforma constitucional sea la expresión del diálogo social, la síntesis construida fruto del desacuerdo y la inclusión (Gargarella, 2004; Nino, 1997; Waldron, 2005).

La tentación del constituyente derivado será liberarse de las cadenas constitucionales o tratar de convertirse en un mejor autor o padre de la constitución cuando en realidad se trata de un poder constituido y restringido a las estrictas disposiciones de la constitución.

ii) El poder constituyente originario como un momento de máxima inclusión y diálogo político para trazar un plan social, un deber ser, para la coexistencia social y el establecimiento de un Estado subordinado a los ciudadanos; por ello se trata de un momento político inigualable, pero no único, pues aunque el constituyente originaria desee que su obra persista en el tiempo, eso supondría convertir en un mandato pétreo, que solo podría ser cumplido y no revisado por las nuevas generaciones. De ahí que la tarea del constituyente derivado sea leer y dialogar con el diseño del constituyente originario. Este puede ser el

9 Véase: Arboleda, P. y Jiménez, M. (2017). La garantía judicial de la constitución. Manizales: Universidad de Caldas. 
momento original y sucesivo de presencia de este constituyente. $\mathrm{Su}$ obra marca precisamente su desaparición al igual que su pervivencia a través del espíritu y la letra de la constitución. Justo este texto puede llamar nuevamente a su conformación como respuesta a las insuficiencias del diseño constitucional; a la necesidad de crear un diseño concreto conforme a los conflictos políticos, sociales y económicos de un determinado Estado; como respuesta a la presión de las fuerzas políticas y distintos factores de poder imperantes en una sociedad, los cuales pueden exigir una nueva distribución del poder (Lasalle, 2010; Sieyes, 2007); ser la consecuencia del ejercicio de la soberanía popular por parte de los ciudadanos, quienes persistentemente ejerciendo su autogobierno y poder deliberativo, pueden instaurar una crítica permanente al poder social y al poder instituido, exigiendo un balance institucional más acorde con la primacía del poder ciudadano; como respuesta a la configuración de un orden democrático o la finalización de conflictos internos o transiciones de dictaduras a democracias en los que haya imperado la fuerza, en estos casos la constitución impone la reordenación de la sociedad y la fijación de la pretensión de un orden justo por lo cual la constitución puede ser denominada como una constitución revolucionaria, o una norma jurídica que plantea las bases para la estabilidad institucional (Ackerman, 2011; Roznai, 2014; Roznai y Jacobsohn, 2020).

Dadas las cosas, mientras el poder constituyente originario tiene un ámbito de plena libertad configurativa únicamente limitada por principios de carácter internacional tales como los derechos humanos, la separación de poderes, el principio de legalidad o el Estado de derecho y el principio democrático; el constituyente derivado posee restricciones expresas e implícitas. Las expresas de carácter procesal centradas en el respeto al procedimiento de reforma, como el inicio de los debates parlamentarios, las mayorías requeridas, la publicidad, la mínima deliberación y el principio de consecutividad. Las implícitas enfocadas en el respeto e imposibilidad de abolición de las decisiones básicas adoptadas por el creador de la constitución en cuanto a la estructura, identidad y principios y derechos de la constitución. Por tanto, la tarea del tribunal constitucional es velar por el cumplimiento de este esquema de creación, modificación y supresión de la constitución. La sustitución de la constitución es un episodio del control de constitucionalidad de las reformas constitucionales que puede producir la inconstitucionalidad con fundamento en el irrespeto a las competencias del constituyente originario. Para sintetizar este argumento, mientras el constituyente originario crea leyes fundamentales el constituyente derivado crea leyes constitucionales ordinarias, esto es, 
leyes que aunque integran la constitución pueden reformarse e incluso abolirse debe persistir y solo pueden ser limitadas proporcionalmente e interpretadas (Schmitt, 1952).

iii) La doctrina de la sustitución de la constitución en la jurisprudencia de la Corte Constitucional de Colombia.

En la Sentencia C-551 de 2003, fundacional de la doctrina de la sustitución de la constitución, se estudió la constitucionalidad de la ley 796 de 2003 - "Por la cual se convoca un referendo y se somete a consideración del pueblo un proyecto de Reforma Constitucional" - . Esta convocatoria a referendo fue realizada por el entonces presidente de la República de Colombia Álvaro Uribe Vélez con el fin de implementar medidas como la pérdida de derechos políticos, la reducción del Congreso y la pérdida de investidura. En esta sentencia se interpretó que la expresión "podrá ser reformada" implica la imposibilidad que la Carta pueda ser sustituida o cambiada por otra, y estableció las diferencias entre reformar y sustituir la Carta, indicando que el Congreso, en su poder de reforma, y el pueblo, en su facultad de decidir democráticamente la suerte de un referendo, carecen de la competencia para sustituir la constitución, pues su poder como órganos constituidos se limita a la potestad de reformarla ${ }^{10}$.

La Constitución limita el poder reformatorio del Congreso y del pueblo, pues la constitución debe conservar su identidad en su conjunto y desde su contenido material, a pesar de las numerosas reformas que se le realicen ${ }^{11}$, ya

${ }^{10} \mathrm{Al}$ respecto, la Corte Constitucional ha sostenido: Esa interpretación contradice el tenor literal de la Constitución. Así, el artículo 374 de la Carta señala que "la Constitución podrá ser reformada...”. Esta disposición, y en general el Título XIII de la Carta, no se refieren a cualquier Constitución sino exclusivamente a la Constitución colombiana de 1991, aprobada por la Asamblea Constituyente de ese año, que actuó como comisionada del poder soberano del pueblo colombiano. De manera literal resulta entonces claro que lo único que la Carta autoriza es que se reforme la Constitución vigente, pero no establece que esta puede ser sustituida por otra Constitución" (Corte Constitucional, Sentencia C-551 de 2003).

${ }^{11}$ Sobre el poder de reforma, véase: "a. El poder de reforma definido por la Constitución colombiana está sujeto a límites competenciales. b. En virtud de esos límites competenciales el poder de reforma puede reformar la constitución, pero no puede sustituirla por otra integralmente distinta u opuesta. c. Para establecer si una determinada reforma a la Constitución es, en realidad, una sustitución de la misma, es preciso tener en cuenta los principios y valores del ordenamiento constitucional que le dan su identidad. d. La Constitución no contiene cláusulas pétreas ni principios intangibles, por consiguiente, todos sus preceptos son susceptibles de reforma por el procedimiento previsto para ello. e. El poder de reforma no puede, sin embargo, derogar, subvertir o sustituir en su integridad la Constitución. f. Sólo el constituyente primario tendría la posibilidad de producir una tal sustitución" (Corte Constitucional, Sentencia C-551 de 2003). 
que lo contrario equivaldría a concebir las reformas no como una actualización, interpretación o complemento de la constitución vigente, sino como su derogación progresiva. Esto significa que el poder de reforma puede modificar cualquier disposición del texto vigente, "pero sin que tales reformas supongan la supresión de la Constitución vigente o su sustitución por una nueva Constitución" (Corte Constitucional, Sentencia C-551 de 2003).

El pueblo adquiere la competencia para reformar la constitución mediante referendo ${ }^{12}$, según lo establece la norma constitucional. En otras palabras, el pueblo, al pronunciarse a través de un referendo, obra dentro de un marco institucional, pero ello no lleva a un quebrantamiento de la estructura jurídica del Estado, como es menester para que entre a operar toda la fuerza del poder constituyente originario, quedando el pueblo para estos efectos relegado a una posición de poder constituido. Iguales restricciones se presumen cunado el pueblo es convocado para avalar y elegir los delegados a una asamblea nacional constituyente parcial o reformatoria.

En tal sentido, al Congreso de la República y al pueblo como constituyente derivados les está prohibido reemplazar la Constitución por una completamente nueva y diferente (Quinche, 2009), de forma que si la identidad básica desaparece o se ve afectada de forma grave, de forma total o parcial, permanente o transitoria ${ }^{13}$. Además, tampoco puede este poder derivado sustituir la esencia de la constitución mediante un cambio parcial ${ }^{14}$ que impida reconocer los elementos esenciales que definen a la constitución misma. No obstante, el poder de reforma puede modificar la constitución dentro los límites (Hernández, 2005; Ramírez, 2005), para actualizar los contenidos constitucionales a las nuevas dinámicas y necesidades de la sociedad.

A continuación se presenta un breve análisis de los principales argumentos utilizados por la Corte Constitucional para fundamentar la doctrina de la sustitución ${ }^{15}$ en las principales sentencias de revisión de la constitucionalidad

${ }_{12}$ El Congreso de la República, por iniciativa del gobierno, o del $5 \%$ del censo electoral de los ciudadanos, mediante ley aprobada por la mayoría de los miembros de ambas cámaras, puede convocar al pueblo para votar por un referendo de un proyecto de reforma constitucional. Se requiere para la aprobación o derogación del referendo la concurrencia del voto de más de la mitad de los sufragantes y que exceda la cuarta parte del total del censo electoral.

${ }^{13}$ Corte Constitucional, Sentencia C-1040 de 2005.

${ }^{14}$ La sustitución puede ser total cuando la Constitución como un todo, es remplazada por otra; o parcial, caso este último en el cual un eje definitorio de la identidad de la Constitución es reemplazado por otro opuesto o integralmente diferente que torna imposible la armonización de la pretendida reforma con el resto de normas constitucionales (Corte Constitucional, Sentencia C-588 de 2009).

${ }^{15}$ De esta manera, mediante la Sentencia C-551 de 2003, la Corte Constitucional estableció la teoría de la sustitución de la constitución; teoría que es desarrollada en las 
de la reforma constitucional, la cual en Colombia se adelanta principalmente a través del acto legislativo.

En la Sentencia C-1040 de 2005 en la que la Corte revisa la constitucionalidad del acto legislativo que creó la reelección presidencial en Colombia, Se utiliza la doctrina de la sustitución constitucional para declarar una sustitución parcial, esto es, que la reelección presidencial inmediata es admisible, pero que delegar funciones legislativas en un órgano judicial como el consejo de estado sustituye la constitución pues desconoce el principio de separación de poderes.

La Corte estima que el juicio de sustitución implica tres fases específicas de evaluación ${ }^{16}$, las cuales en ningún momento pueden promover la creación jurisprudencial de cláusulas pétreas o la revisión del contenido material de la reforma. Adicionalmente se especifica que el juicio de sustitución es un juicio hermenéutico, un discernimiento judicial de la estructura e identidad implícita de la constitución; un juicio de constitucionalidad distinto del control de constitucionalidad de las leyes, ya que en la revisión judicial de la reforma constitucional solo se revisan los vicios de forma. En el juicio de sustitución se revisa bajo una perspectiva de imparcialidad judicial si: a) si la reforma introduce un nuevo elemento esencial a la Constitución, (b) si se analiza si éste reemplaza al originalmente adoptado por el constituyente y, luego, (c) si se compara el nuevo principio con el anterior para verificar, no si son distintos, lo cual siempre ocurrirá, sino si son opuestos o integralmente diferentes, al punto que resulten incompatibles (Corte Constitucional, Sentencia C-1040 de 2005). Tesis similar es promovida en la Sentencia C-588 de 2009 en la que se estima como premisa mayor del juicio de sustitución la determinación de cuál es el elemento reemplazado e indicar, a partir de múltiples referentes normativos, cuáles son sus especificidades en la Carta de 1991, y, evitar la consagración de cláusulas pétreas las cuales no existen en el ordenamiento constitucional. La jurisprudencia constitucional dispone que la sustitución de la constitución se centra en el respeto de la jerarquía constitucional, la primacía normativa y la ausencia de elementos supraconstitucionales para definir la constitucionalidad de una reforma. Así se concibe los tratados internacionales que integran el bloque de constitucionalidad como

sentencias C-1200 de 2003, C-970 y C-971 de 2004; la C-242 de 2005, la C-1040 de 2005, C-588 de 2009, C-141 de 2010, C-574 de 2011, C-249 de 2012, C-1056 de 2012 C-579 de 2013, C-577 de 2014, C-053 de 2016, C-261 de 2016, C-285 de 2016, C-230 de 2016, C-379 de 2016, C-094 de 2017, C-699 de 2016, C-332 del 2017, C-630 de 2017, C-674 de 2017, C-020 de 2018, C-076 de 2018 y Sentencia C-245 de 2019.

${ }^{16}$ La Sentencia C-970 de 2004 y la Sentencia C-971 de 2004, son relevantes ya que afincan el concepto de control sobre vicios de forma, especialmente el vivido de competencia al poder de reforma al ejecutar el control constitucional. Además, por contribuir a la construcción del test de sustitución. 
criterios orientadores de la actividad judicial y de la determinación de los principios esenciales de la constitución que pueden resultar lesionados con un ejercicio desproporcionado de las facultades del poder de reforma.

En síntesis, las sentencias C-588 de 2009, C-574 de 2011 y C-288 de 2012 han establecido tres pasos denominados premisa mayor, premisa menor y premisa de síntesis. Pasos recopilados siguiendo la forma de un silogismo mediante Sentencia C-1056 de 2012:

i) En la primera se debe presentar los elementos que se estiman han sido afectados por la reforma constitucional;

ii) la segunda debe identificar los nuevos aspectos introducidos por la reforma y que generan un reemplazo del texto constitucional.

iii) La tercera, debe enunciar la conclusión conforme a la cual unos y otros elementos resultan abiertamente incompatibles (Corte Constitucional, Sentencia C-1056 de 2012).

El Tribunal constitucional estableció una doctrina que le permite revisar reformas especificas a la constitución, sin embargo, esta figura solo ha iniciado su desarrollo, y solo los casos evaluados a lo largo de las décadas permitirán establecer una doctrina correctamente afincada tanto en sus principios como en las restricciones en la discrecionalidad del juzgador, y a la par de respeto y prevalencia del principio democrático ${ }^{17}$. La sustitución pretende prevenir que la constitución sea transformada en otra completamente distinta y que se introduzcan nuevos elementos que reemplazan totalmente o parcialmente las decisiones adoptadas por el constituyente originario. La Corte dispuso que para establecer si hay o no sustitución es necesario identificar los principios y valores que la constitución posee, y confrontarlos con los introducidos o desplazados por la reforma constitucional, con el fin de determinar si pueden coexistir o por el contrario sean incompatibles (Corte Constitucional, Sentencia C-588 de 2009).

Este pronunciamiento reconoce la importancia de complementar el juicio de sustitución con el juicio de efectividad ${ }^{18}$. Este test pretende mantener la primacía del imperio de la constitución y la ley, la vigencia del Estado De

${ }_{17}$ Corte Constitucional, Sentencia C-588-2009. Cuestión también reconocida en Sentencia C-141 de 2010.

18 Aplicado el test de efectividad de la reforma al Acto Legislativo que adiciona un parágrafo transitorio al artículo 125 superior, que para la Corte opera plenamente, no avala el carácter de reforma con el que se buscó presentar al artículo demandado, porque: de una parte, el parágrafo añadido dejó intacto el texto del artículo, y de otro lado, pese a las notables implicaciones del parágrafo demandado en el ámbito de sus efectos, el texto de los artículos 2, 13, 40-7, 53, 150, 209, para citar unos cuantos, permanece inalterado después de la supuesta reforma que el Congreso quiso introducir valiéndose del Acto Legislativo 01 de 2008 
Derecho y el carácter imparcial del sistema jurídico, repudiando por tanto reformas que encubran decisiones políticas ad hoc o que traten de beneficiar ciertas instituciones o personas.

La Corte Constitucional posteriormente volvió a revisar la reelección presidencial - Sentencia C-141 de 2010 - tras la propuesta de un referendo constitucional mediante ley convocatoria (Ley 1354 de 2009) estimando la posibilidad de la sustitución de la constitución por el desconocimiento del principio republicano, la separación de poderes, pesos y contrapesos y el principio democrático ${ }^{19}$, pues la posibilidad de la reelección por más de dos periodos implicaba la reducción o minimización de la oposición política. En esta sentencia la Corte identificó estos principios como contenidos esenciales de la constitución, recogiendo parte de la jurisprudencia que se había desarrollado a partir de la Sentencia C-551 de 2003, desde la cual ya se reconocían como principios estructurales el de méritos ${ }^{20}$, de separación de poderes, democrático, sistema de pesos y contra pesos; además, se reitera la metodología del test de sustitución y de efectividad.

Adicionalmente, la Sentencia C-141 de 2010 constituye un hito no solo por declarar que la reelección inmediata es una figura que sustituye la constitución, por fijar implícitamente un límite para el ejercicio del poder político presidencial, sino también porque reconoce que el juicio de sustitución y de efectividad son una evaluación constitucional normativa y política; a la par, por reconocer el posible uso de la reforma constitucional con fines abusivos o personales, lo que supone distorsionar el sistema jurídico y el poder de reforma. Asimismo, la doctrina de la sustitución de la constitución fija límites para la democracia constitucional, declarando la imposibilidad de admitir una democracia plebiscitaria o simplemente mayoritaria y en su

19 Esta circunstancia reaviva el debate sobre la dificultad contramayoritaria, ya que sin duda, goza de mayor legitimidad democrática el pueblo para realizar algún tipo de reforma, que la Corte como poder derivado para limitar el poder de reforma. Al respecto, es importante citar la aclaración de voto de Rodrigo Uprimny Yepes en sentencia C-572 de 2004, donde expresó: "Por ello, a pesar de que es claro que el poder de reforma se encuentra limitado por la prohibición de afectar la estructura básica de la constitución, como ya se explicó, considero que por las vías extraordinarias de reforma constitucional (referendo y asamblea constituyente) es posible entrar a modificar incluso la estructura básica de la Constitución, pues la aprobación ciudadana de esas modificaciones implica una cierta intervención del poder constituyente originario pero, por paradójico que parezca, de manera institucionalizada" (Corte Constitucional, Sentencia C-572 de 2004).

${ }^{20}$ Corte Constitucional, Sentencia C-249 de 2012. Esta sentencia declaró inconstitucional la reforma que establecía una forma de concurso, pero en donde la permanencia era el criterio fundamental. Principio de mérito, concurso público, igualdad. Esta sentencia es relevante porque hace un balance a la fecha acerca de la doctrina de la sustitución y del instrumento denominado test de sustitución. 
lugar exigiendo una democracia basada en el pluralismo político y en la deliberación.

En la Sentencia C-1056 de 2012 la Corte Constitucional inicia la modulación del control de constitucionalidad del poder de reforma, reconociendo la existencia de un doble peligro. De un lado, la posibilidad que en pro de defender la constitución termine petrificando la Constitución, impidiendo así la consagración del resultado del proceso democrático. Del otro lado, la posibilidad que el juez constitucional aplique una discrecionalidad excesiva y termine restringiendo la práctica democrática que da origen a la reforma constitucional, generando una apropiación de la constitución por parte de quien se presume es su guardián.

A su vez en la Sentencia C- 288 de $2012^{21}$ se reitera la necesidad de tomar precauciones en el ejercicio del juicio de constitucionalidad, para lo cual se promueven tres mecanismos:

i) cualificación de la acción pública de inconstitucionalidad, lo cual puede terminar siendo problemático pues la constitución y el decreto 2067 de 1991 exigen requisitos generales y accesibles a cualquier ciudadano, en cambio la jurisprudencia ha creado la teoría de los cargo de constitucionalidad y una técnica especial para las demandas a los actos legislativos los que supone una carga especial y adicional al ciudadano que lo distancia del justicia constitucional ${ }^{22}$.

${ }^{21}$ Esta sentencia reconoce también como principios fundamentales, los siguientes: "El principio democrático, contenido de manera concordante en el preámbulo y en el artículo $1^{\circ}$ del texto superior, conforme al cual las decisiones públicas deben ser adoptadas según lo que convenga o interese al pueblo, que conforme al artículo $3^{\circ}$ ibídem, es el titular de la soberanía y el origen del poder público; el segundo, la prevalencia del interés general, mencionado por el artículo $1^{\circ}$ como uno de los elementos fundantes del Estado, y la justicia y el bien común, que conforme al artículo 133 deben motivar las actuaciones de las corporaciones públicas, parámetros que en tal medida condicionan la totalidad de la actuación, tanto de los servidores públicos como de los particulares; y por último, el principio de separación de poderes, enunciado por el artículo 113 y desarrollado en forma detallada especialmente por las disposiciones contenidas en los Títulos V a VIII de la misma obra, principio que según su nombre lo indica, y en directa concordancia con el anterior, busca evitar la concentración del poder y de las decisiones públicas en unos mismos sujetos, así como garantizar el mutuo control entre los servidores públicos, con el ánimo de promover, potenciar y llevar a su plenitud los valores democráticos. La importancia sin igual de estos tres elementos dentro de nuestro modelo constitucional en ningún caso podría resultar exagerada, como tampoco la íntima conexión existente entre ellos, tal como lo demuestran los amplios desarrollos que al respecto ha vertido la jurisprudencia de esta corporación" (Corte Constitucional, Sentencia C-288 de 2012).

22 En la Sentencia C-373 de 2016 se precisan estos requisitos de la siguiente manera: “a) El planteamiento debe ser claro de manera que la ilación de ideas permita entender cuál es el sentido de la acusación en contra del acto reformatorio. b) El cuestionamiento 
ii) Necesidad de conservar la precisión conceptual sobre la materia, esto es, esgrimir argumentos que solo se centren en el juicio por vicios de forma que le compete a la Corte y no en vicios materiales.

iii) Sujeción a una metodología particular para adelantar el juicio de sustitución.

Las sentencias C-285 de 2016 y C-373 de 2016 evaluaron el Acto Legislativo 02 de 2015 que pretendía una reforma constitucional en pro de un mayor equilibrio de poderes.

En este caso se estimó que existía una sustitución parcial de los principios de separación de poderes, autonomía e independencia judicial ${ }^{23}$, pues aunque se reconoce la discrecionalidad y la capacidad democrática del Congreso para ejecutar la reforma constitucional y, entre los posibles tópicos, reformar e incorporar modelos de gestión judicial, incluso pudiendo suprimir órganos creados originariamente por el poder constituyente (eliminar el Consejo Superior de la Judicatura y reemplazarlo por el Consejo de Gobierno Judicial), el constituyente derivado no puede extralimitarse y eliminar o reducir al máximo sin justificación suficiente las leyes o principios fundamentales que soportan la constitución. Esto implica un vicio de competencia pues el constituyente derivado al tratar de abolir o limitar desproporcionadamente un principio transversal y estructural de la constitución usurpa las funciones exclusivas del constituyente originario; dota al poder de reforma de un poder que solo puede usar legítimamente el constituyente originario. Situación que

requiere ser cierto y, en esa medida, el acto reformatorio de la Constitución debe existir jurídicamente y encontrarse vigente. Adicionalmente, los contenidos que se le atribuyen deben derivarse de su texto. No puede fundarse su argumentación en la suposición de normas, en interpretaciones conjeturales del acto reformatorio o en premisas evidentemente falsas o inconsecuentes. c) El razonamiento debe ser pertinente y, en consecuencia, debe tratarse de un verdadero cargo que ponga de presente la infracción de las normas constitucionales relacionadas con la competencia del Congreso de la República para reformar la Carta. d) Como condición de suficiencia del cargo, los demandantes deben esforzarse por presentar de manera específica las razones por las cuales la aprobación del acto reformatorio de la Constitución por parte del Congreso, desconoce las normas que le atribuyen su competencia. Así, el examen judicial por sustitución supone identificar un eje definitorio que no se desprende directamente de una disposición de la Carta sino que exige una interpretación constitucional sistemática" (Corte Constitucional, Sentencia C-373 de 2016).

${ }^{23}$ Corte Constitucional, Sentencia C-285 de 2016. En esta sentencia se establece que “en la Constitución de 1991, el principio de autogobierno judicial comprende tres elementos: (i) Por un lado, la existencia de una institucionalidad encargada del gobierno y administración del poder judicial; (ii) por otro lado, se requiere que dichas instancias sean endógenas al poder judicial, es decir, que se inserten a la estructura de dicho poder; (ii) y finalmente, estas instancias deben tener la capacidad para dirigir y gestionar la Rama Judicial considerada como órgano y como función de administración de justicia”. 
hace procedente el control jurisdiccional de la constitución frente a la reforma de la constitución.

\section{DOCTRINA DE LA SUSTITUCIÓN EN EL RÉGIMEN JURÍDICO DE PAZ}

Desde el 2012 la Corte Constitucional mediante el control constitucional sobre actos legislativos, específicamente sobre el acto legislativo 01 de 2012 (marco jurídico para la paz ${ }^{24}$ ) y los actos legislativos 01 de 2016 y 2017 (instrumentos jurídicos para la implementación del acuerdo final y la construcción de una paz estable y duradera), ha continuado con el desarrollo y la aplicación de la teoría de la sustitución de la constitución.

En este ámbito se ha cuestionado que los acuerdos de paz podrían haber sustituido la constitución, ya que por ejemplo, incorporan un sistema de justicia especial, o transicional, que generaría impunidad frente a crímenes de lesa humanidad, o llevaría a encubrir otros como el narcotráfico bajo la idea de conexidad con los delitos políticos que motivaron el conflicto. Al tener que regularse muchos de los acuerdos con reformas constitucionales la sustitución ha sido un argumento que merece respuesta (Colón Ríos, 2013). La sustitución se convierte en una teoría que hace que el control de constitucionalidad bajo una revisión formal determine si el constituyente derivado ha usurpado las competencias del constituyente originario, desconociendo los principios esenciales de la constitución, en este caso, el principio democrático y la reparación integral de las víctimas como derecho fundamental.

$\mathrm{Al}$ respecto, el acto legislativo 01 de 2012 fue revisado por la Corte Constitucional en C-579-13, promovida por una acción pública de inconstitucionalidad en la que los demandantes solicitaban la inconstitucionalidad del mismo argumentando que el marco jurídico para la paz sustituye el deber del Estado colombiano de garantizar los derechos humanos y de investigar y juzgar todas las graves violaciones de derechos humanos e infracciones al Derecho Internacional Humanitario.

La Corte Constitucional aplicó el juicio de sustitución con la finalidad de identificar si éste Acto Legislativo se enmarcaba en una extralimitación de competencias del Congreso de la República al momento de modificar la Constitución de 1991. Al respecto, en las consideraciones de la Corte se evidencia que el fundamento para la conclusión negativa en el juicio de sustitución, radica en la consideración o énfasis en el deber de garantía de los

${ }^{24}$ Demanda de inconstitucionalidad contra el artículo $1^{\circ}$ (parcial) y el artículo $3^{\circ} \mathrm{del}$ Acto Legislativo 1 de 2012 "Por medio del cual se establecen instrumentos jurídicos de justicia transicional en el marco del artículo 22 de la Constitución Política y se dictan otras disposiciones". Véase: Corte Constitucional, Sentencia C-577 de 2014. 
derechos y no en la persecución penal de los responsables de graves violaciones a los mismos y al derecho internacional humanitario. El juez constitucional estimó frente a este caso que el poder punitivo no representa una garantía para los derechos de las víctimas del conflicto armado interno, sino que es uno de los medios estatales para coaccionar y promover su satisfacción; por tanto, el fin o principio estructural es la protección y reparación integral de las víctimas, ámbito dentro del cual el Estado y el poder de Reforma puede utilizar otros medios, como el que implica la justicia transicional; en consecuencia, la Alta Corte declaró la exequibilidad del inciso cuarto del artículo $1^{\circ}$ del Acto legislativo 01 de $2012^{25}$.

Debe indicarse que el control del tribunal constitucional sobre los acuerdos de paz y, bajo el entendido de una justicia transicional, debe ser determinante en las reformas constitucionales orientadas a implementarlo, más cuando se está en presencia de un constitucionalismo transicional, es decir, de un proceso de implementación normativa, pero en vigencia de una constitución permanente, lo que resulta atípico para el caso Colombiano, pues en uno de los referentes más ilustrativos, el Sudafricano (1993), el proceso se cumplió bajo una constitución o normativa transitoria (Bernal et al. 2016).

Mediante el acto legislativo 01 de 2016 se establecía autorizar la reducción del procedimiento parlamentario, permitiendo la votación en bloque del articulado de las normas que pretendieran la implementación de los acuerdos de paz, y en consecuencia, la limitación excesiva del principio de mínima deliberación parlamentaria (Trámite rápido de reforma constitucional — fast track $^{26}$-). Esta facultad fue declarada inicialmente constitucional por la Corte Constitucional a través de la Sentencia C-699 de 2016 bajo la concepción de que podían ser tolerables conforme al fin de la paz; posteriormente a través de nuevos cargos, la Corte estimó que desconocía de forma flagrante de la separación de poderes y la libre configuración legislativa que radica en poder del Presidente la fijación de la agenda legislativa, el establecimiento de proyecto de ley y el control de sus modificaciones ${ }^{27}$, por lo que declaró su inconstitucionalidad ${ }^{28}$. Lo que evidencia la pertinencia de la refrendación popular de un acuerdo de paz, pero a la par, la vigilancia judicial de que los acuerdos de paz no desconozcan los principios esenciales de la constitución, más en el marco de un constitucionalismo transicional.

25 Véase: Corte Constitucional, Sentencia C-579 de 2013.

${ }^{26}$ El fast track es un procedimiento legislativo especial para la implementación de la paz, y simplifica el trámite de los proyectos de ley y actos legislativos. Esta facultad tenía una vigencia de seis meses, prorrogables por otros seis meses a partir de la vigencia del acto legislativo (Quinche, 2017).

27 Véase: Corte Constitucional, Sentencia C-160 de 2017.

${ }^{28}$ Véase: Corte Constitucional, Sentencia C-332 de 2017. 
Así, el Gobierno y el Legislador deben armonizar las normas de implementación de los acuerdos de paz y la justicia transicional a la luz del régimen constitucional permanente. Este esquema de justicia transicional puede, siendo validado democráticamente - no necesariamente en lo electoral, si representativamente como procedió en Colombia con el acto legislativo 01 de 2012 (marco jurídico para la paz) y los actos legislativo 01 de 2016 y 2017-, ser admisible sin que se entienda que desplaza a la jurisdicción, siempre que se trate de un modelo especializado y temporal ${ }^{29}$.

Para la Corte el esquema de justicia transicional (justicia especial para la paz como se le denominó) debe responder a un carácter excepcional, lo que implica, conforme a la Sentencia C-577 de 2014 (i) que las mismas no reemplazan el régimen constitucional existente, que continúa vigente; (ii) y que las reglas relativas a la posibilidad de participar en política únicamente tendrán efectos respecto de quienes se desmovilicen en el marco de un proceso de paz (parágrafo $1^{\mathrm{o}}$ del artículo transitorio 66 de la Constitución) ${ }^{30}$.

Las sentencias C-699 de 2016 y C-332 de 2017 impulsan la aplicación del principio de unidad de la Constitución, como un deber del intérprete constitucional para fundamentar un texto armónico y coherente, debe ser interpretado de manera sistemática y respetando los fines perseguidos por el constituyente. Este principio regula tanto la demanda como la evaluación de la reforma constitucional, la cual debe ser interpretada de forma coherente, esto es, de acuerdo al objetivo perseguido por su autor y a la estructura filosófica e identitaria de la constitución ${ }^{31}$. Un cuestionamiento a la reforma constitucional debe estar basado en un análisis integral del texto de la reforma y del texto de la constitución, evidenciando la ausencia de interpretaciones fragmentadas.

Así mismo, el Tribunal constitucional sigue promoviendo el uso del test de sustitución y respetando los antecedentes jurisprudenciales que lo fundaron ${ }^{32}$ :

29 Véase: Corte Constitucional, Sentencia C-577 de 2014. Bernal, C. (2009). El Neoconstitucionalismo y la normatividad del Derecho. Bogotá: Universidad Externado de Colombia. Bernal, C. (2018). Derechos, cambio constitucional y teoría jurídica. Bogotá: Universidad Externado de Colombia.

30 Véase: Congreso de la República, Ley 1592 de 2015. Congreso de la República, Acto legislativo 01 de 2016. Congreso de la República, Acto legislativo 01 de 2017. Corte Constitucional, Sentencia C-674 de 2017. A través de una ley reglamentaria de la justicia transicional o justicia especial para la paz se definen las penas, garantías y derechos de las víctimas, estructura de la jurisdicción transitoria, y régimen de libertad y amnistías.

31 Véase: Albert, R. (2017). Formas y función de la enmienda constitucional. Bogotá: Universidad Externado de Colombia. Albert, R. (2019). Constitutional amendments. Making, breaking, and changing constitutional. New York: Oxford University Press..

32 Corte Constitucional, Sentencia C-970 de 2004. Corte Constitucional, Sentencia C-971 de 2004. 


\section{Premisa mayor:}

(i) Expresar con suma claridad los principios esenciales de la constitución presuntamente infringidos.

(ii) Fundamentar los principios esenciales identificados a partir de múltiples referentes normativos que muestren cuáles son sus especificidades en la Carta de 1991;

(iii) Justificar los principios esenciales identificados como definitorios de la identidad de la Constitución integralmente considerada;

(iv) no poder reducirse a un artículo del orden constitucional para así evitar que éste sea transformado por la propia Corte en cláusula pétrea a partir de la cual efectúe un juicio de contradicción material;

(v) no equivaler a la fijación de límites materiales intocables por el poder de reforma.

\section{Premisa menor:}

(vi) Expresar qué poder constituido expidió el actor reformatorio de la Constitución y las características básicas de la enmienda; es decir, su alcance jurídico, en relación con los elementos definitorios identificadores de la Constitución.

\section{Síntesis}

(vii) Confrontadas ambas premisas, debe determinarse si el elemento definitorio expresado en la premisa mayor es reemplazado por otro y el nuevo es opuesto o integralmente diferente al anterior, al punto que resulte incompatible con la Constitución de 1991.

La Corte Constitucional ha afinado su jurisprudencia, no solo para precisar los instrumentos que le permiten realiza el juicio de sustitución, sino también para reiterar la naturaleza de su juicio, el cual en ningún caso obedece a un control material. Control forma, competencial, que consiste en un examen que se realiza en función de la competencia y en atención a los términos en que está se encuentra reconocida, para establecer si el órgano reformador atendió los límites de su atribución, aunque haya cumplido a cabalidad los distintos pasos del procedimiento que permiten realizar la reforma constitucional (Corte Constitucional, Sentencia C-332 de 2017).

Este refinanciamiento de la doctrina de la sustitución también ha implicado realzar el principio de autorestricción judicial, con el fin de evidenciar que el guardián de la constitución no se extralimita, ni va más allá de los límites que le fija la propia constitución. Esto, al menos en teoría. El reconocimiento del principio de autorestricción judicial implica satisfacer 3 objetivos: i) amparar la identidad de la Constitución de ejercicios arbitrarios del poder de reforma que transformen sus ejes definitorios; (ii) permitir que la Carta se 
adapte a los cambios sociopolíticos más trascendentales, mediante el uso de los mecanismos de reforma de la Constitución; (iii) evitar, de forma estricta, que el límite competencial derivado de la prohibición de sustitución se confunda con un control material de las reformas constitucionales (Corte Constitucional, Sentencia C-332 de 2017).

Ahora bien, en la Sentencia C- 027 de $2018^{33}$ se dan lineamientos para la construcción constante de la doctrina de la sustitución constitucional. En esta sentencia se aborda la aparente falta de claridad respecto a los ejes definitorios de la constitución. Si bien el constituyente no estableció expresamente ni principios axiales, ni ejes definitorios en la constitución, estos se han venido definiendo a través de la jurisprudencia de la Corte. Esto puede evidenciar una contradicción ya que si el poder de reforma es un poder derivado que no puede afectar principios axiales de la constitución, tampoco un órgano instituido como la Corte Constitucional, pese a ser el guardián de la carta, puede otorgarse competencias para establecer dichos ejes definitorios, ya que el texto constitucional no lo ha establecido, lo que podría generar una extralimitación de la Corte y un desconocimiento de la primacía de la constitución, especialmente en su capacidad de restringir las actuaciones de los servidores públicos.

La Corte Constitucional para establecer si existe un vicio competencial, realiza un análisis material o de fondo de la Constitución, cuando define si se están afectando o no principios axiales de la norma superior. Por tanto, la Corte acude a una argucia jurídica para afirmar que cuando establece el vicio de competencia, no realiza control material, sino formal o de procedimiento. Evidentemente eso es una falacia, ya que cuando la Corte contrasta los principios, valores o ejes definitorios de la constitución quebrantados, con el texto de la reforma, pues inequívocamente se estará realizando un control material al acto reformatorio. En todo caso, los límites entre el vicio de forma o de fondo son casi que irreconocibles en materia de reforma constitucional.

La Corte ha venido estableciendo a través de su jurisprudencia unos ejes definitorios de la identidad de la constitución. En tal sentido, ha dicho que son ejes axiales por ejemplo, el estado social de derecho, el principio de separación de poderes, el principio de legalidad, el principio de pesos y contrapesos, el principio democrático, el autogobierno judicial, la autonomía territorial, el pluralismo político, el principio republicano y hasta el principio de mérito en la carrera administrativa. En este orden de ideas, también se podría establecer como un eje definitorio el poder de reforma de la Constitución. Cualquier cambio a este eje axial, podría considerarse como una sustitución a la constitución. Siguiendo la argucia jurídica de la Corte, con un poco de sensatez

33 También véase las siguientes sentencias: Corte Constitucional, Sentencia C-630 de 2017. Corte Constitucional, Sentencia C-674 de 2017. Corte Constitucional, Sentencia C-020 de 2018. Corte Constitucional, Sentencia C-076 de 2018. 
racional, se podría elevar a eje definitorio el poder de reforma de la Carta y la no existencia de cláusulas pétreas. El constituyente del 91, si bien estableció unos requisitos formales a los mecanismos de reforma, no estableció límites materiales. El poder de reforma debería tener la flexibilidad que el control democrático le permita, para que la constitución se pueda adaptar a los diferentes cambios políticos, sociales y económicos. Es decir, la garantía jurisdiccional de la constitución debe ser una garantía nuclear, que intervenga en casos extremos, que actúe como un seguro frente a consecuencias indeseadas en una democracia constitución, por ejemplo, aquellas que pretendan eliminar el proceso democrático o los derechos fundamentales; en tanto que el control democrático, participativo y deliberativo, debería convertirse en la regla general para vigilar la constitución promover su desarrollo y respeto por los distinto factores de poder institucional y social.

\section{CONCLUSIONES}

El constituyente de 1991 estableció tres vías de reforma a la Carta Política, la cuales si bien, establecen algunas formalidades, en ningún caso se les impuso algún tipo de límite expreso. Es decir, no se establecieron cláusulas pétreas en la Constitución de 1991. Se recuerda que estas cláusulas de intangibilidad son aquellos conceptos de la constitución que no pueden ser objeto de reforma. Sin embargo, a partir de la jurisprudencia de 2003, la Corte Constitucional acogió la tesis que el poder de reforma no puede sustituir la constitución. A partir de allí, la Corte comienza a construir una línea jurisprudencial que le ha permitido definir el objeto y procedencia del juicio de sustitución.

La Constitución en su artículo 241 establece que la Corte Constitucional tiene la facultad de realizar la revisión constitucional de los actos reformatorios de la Constitución por vicios de forma o procedimentales. De esta manera, la Corte - desde 1992 - no realizó la revisión material o competencial de los actos legislativos hasta que en la Sentencia C-551 de 2003 señaló que las reglas de competencia impiden que la constitución sea sustituida por otra diferente. En esta sentencia la Corte expresa que el control constitucional sobre las reformas constitucionales recae entonces sobre el procedimiento de reforma y no sobre el contenido material del acto reformatorio. Empero, desde el 2003 a 2020, la Corte ha venido precisando y fomentando la evolución de la doctrina de la sustitución, particularmente, dependiendo que su intervención no puede constituir un control material, sino únicamente sobre los vicios de forma o procedimentales. Al respecto estableció que el vicio de forma o de procedimiento contiene dos tipos de defectos que son posibles de identificar sin tener que confrontar el contenido de la ley con la norma superior: (i) Vicios de trámite o relativos al curso del acto reformatorio; y (ii) vicios de competencia para emitir determinados contenidos 


\section{Diagrama de desarrollo jurisprudencial sobre la Doctrina de la Sustitución constitucional en Colombia}

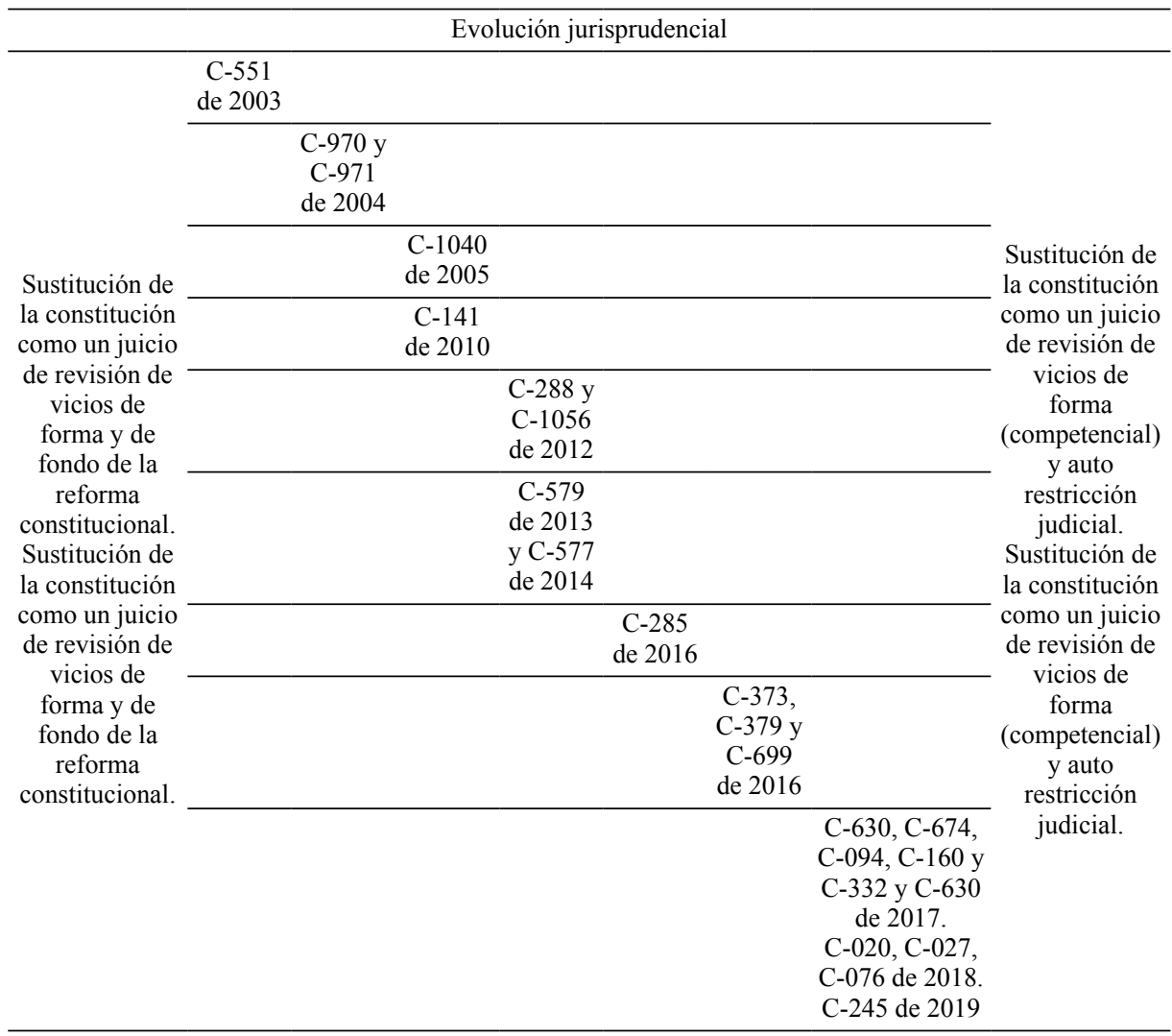

constitucionales. Por lo tanto, con dicho argumento, la Corte justifica que el control competencial, también es un control formal o de procedimiento, cuyo objetivo consiste en evitar que el constituyente derivado usurpe las competencias del constituyente originario, esto es, que el reemplazo o la limitación excesiva de una ley fundamental, principio esencial y transversal de la constitución, o su estructura, identidad y derechos solo le corresponde a una Asamblea Nacional Constituyente total; en tanto que la interpretación, ajuste, complemente, modificación e interpretación de la constitución puede ser una tarea del poder de reforma. Al cual le corresponde mantener un diálogo con la filosofía y las determinaciones adoptadas por el autor de la constitución. 
Finalmente, la evolución jurisprudencial ha reconocido la necesidad de establecer mecanismos de restricción judicial para no menguar la prevalencia de las competencias constitucionales y democráticas concedidas al poder de reforma. La naturaleza del juicio de constitucionalidad, el test de sustitución y efectividad evidencia el acercamiento a una revisión judicial moderada, que cada vez más requiere una notoria usurpación de las competencias constitucionales para emitir un reproche sobre el producto democrático dado en el cambio constitucional. La Corte debe seguir fortaleciendo las bases racionales y razonables del juicio constitucional sobre el poder de reforma, con el propósito de incrementar su legitimidad y armonizar sus actuaciones con la prevalencia del principio democrático.

\section{REFERENCIAS BIBLIOGRÁFICAS}

ACKerman, B. (2011). La Constitución Viviente. Madrid: Marcial Pons.

Albert, R. (2017). Formas y función de la enmienda constitucional. Bogotá: Universidad Externado de Colombia.

(2019). Constitutional amendments. Making, breaking, and changing constitutional. New York: Oxford University Press.

ARBOLEDA, P. y JimÉNEZ, M. (2016). Una aproximación a la filosofía política de la cláusula democrática en la Constitución de 1991. Revista Filosofia UIS, (15), 19-46.

- (2017). La garantía judicial de la Constitución. Manizales: Universidad de Caldas.

Bernal, C. (2009). El Neoconstitucionalismo y la normatividad del derecho. Bogotá, Universidad Externado de Colombia.

- (2018). Derechos, cambio constitucional y teoría jurídica. Bogotá: Universidad Externado de Colombia.

Bernal, C., Barbosa, G. y Ciro, A. (2016). Justicia Transicional: Retos Teóricos (vol. 1). Bogotá: Universidad Externado de Colombia.

Bobbio, N. (1992). El futuro de la democracia (Trad. J. Fernández Santillán). Bogotá, Colombia: Fondo de Cultura Económica.

Colombia. Congreso de la República. Acto legislativo 01 de 2016. Acto legislativo 01 de 2017.

Colombia, Corte Constitucional, Sentencia C-544 de 1992. MP: Alejandro Martínez Caballero.

- Sentencia C-037 de 1996. MP: Vladimiro Naranjo Mesa.

- Sentencia C-037 de 2000. MP: Vladimiro Naranjo Mesa.

Sentencia C-1290 de 2001. MP: Álvaro Tafur Galvis.

- Sentencia C-207 de 2003. MP: Rodrigo Escobar Gil.

- Sentencia C-551 de 2003. MP: Eduardo Montealegre Lynett.

Sentencia T-688 de 2003. MP: Eduardo Montealegre Lynett.

_ Sentencia C-1200 de 2003. MP: Manuel José Cepeda Espinosa. Rodrigo Escobar Gil.

- Sentencia C-572 de 2004. MP: Rodrigo Uprimny Yepes. Recuperado de http://www.corteconstitucional.gov.co/relatoria/2004/C-572-04.htm 
- Sentencia C-970 de 2004. MP: Rodrigo Escobar Gil.

- Sentencia C-971 de 2004. MP: Manuel José Cepeda Espinosa.

Sentencia C-242 de 2005. MP: Álvaro Tafur Galvis.

— Sentencia C-1040 de 2005. MP: Manuel José Cepeda Espinosa.

- Sentencia C-398 de 2006. MP: Alfredo Beltrán Sierra.

- Sentencia C-588 de 2009. MP: Gabriel Eduardo Mendoza Martelo.

- Sentencia C-141 de 2010. MP: Humberto Antonio Sierra Porto.

— Sentencia C-574 de 2011. MP: Juan Carlos Henao Pérez.

- Sentencia C-288 de 2012. MP: Luis Ernesto Vargas Silva.

- Sentencia C-249 de 2012. MP: Juan Carlos Henao Pérez.

- Sentencia C-1056 de 2012. MP: Nilson Pinilla Pinilla.

- Sentencia C-579 de 2013. MP: Jorge Ignacio Pretelt Chaljub.

— Sentencia C-577 de 2014. MP: Martha Victoria Sáchica.

Sentencia C-053 de 2016. MP: Alejandro Linares Cantillo.

_ Sentencia C-261 de 2016. MP: Luis Guillermo Guerrero Pérez.

— Sentencia C-285 de 2016. MP: Luis Guillermo Guerrero Pérez.

- Sentencia C-699 de 2016. MP: María Victoria Calle Correa.

Sentencia C-230 de 2016. MP: Alberto Rojas Ríos.
Sentencia C-373 de 2016. MP: Alejandro Linares Cantillo. Gabriel Eduardo

Mendoza Martelo.

- Sentencia C-379 de 2016. MP: Luis Ernesto Vargas Silva.

Sentencia C-094 de 2017. MP: Aquiles Arrieta Gómez.

- Sentencia C-160 de 2017. MP: Gloria Stella Ortiz Delgado.

— Sentencia C-332 de 2017. MP: Antonio José Lizarazo Ocampo.

Sentencia C-630 de 2017. MP: Luis Guillermo Guerrero Pérez. Antonio José

Lizarazo Ocampo.

— Sentencia C-674 de 2017. MP: Luis Guillermo Guerrero Pérez.

- Sentencia C-020 de 2018. MP: Carlos Bernal Pulido.

- Sentencia C-076 de 2018. MP: Alberto Rojas Ríos.

Sentencia C-245 de 2019. MP: Alejandro Linares Cantillo.

Colón Ríos, J. (2013). La Constitución de la democracia. Bogotá: Universidad Externado de Colombia.

Ferrajoli, L. (2014). La democracia a través de los derechos. Madrid: Trotta.

Gargarella, R. (2004). Constitución y democracia. En S. Albanese, A. Dalla, R. Gargarella, A. Hernández y D. Sabsay (orgs.), Derecho Constitucional (págs. 6985). Buenos Aires: Editorial Universidad.

GuAstini, R. (2010). Teoría e ideología de la interpretación constitucional. Madrid: Trotta.

HernáNDeZ, J. G. (2005). Reformas constitucionales inconstitucionales. Cali: Universidad Santiago de Cali.

Hesse, K. (1983). Escritos de derecho constitucional. Madrid: Centro de estudios constitucionales.

Kelsen, H. (1995). Teoría general del derecho y del Estado. México: UNAM.

Lasalle, F. (2010). Qué es una Constitución?. Bogotá: Editorial Temis.

Nino, C. (1997). La constitución de la democracia deliberativa. Barcelona: Gedisa. 
Quinche, M. F. (2009). La elusión constitucional: una política de evasión del control constitucional en Colombia. Bogotá: Universidad del Rosario. (2017). Reformismo constitucional. Bogotá: Ibáñez.

Ramírez, G. (2005). Límites de la reforma constitucional en Colombia: el concepto de constitución como fundamento de la restricción. Bogotá: Universidad Externado de Colombia.

RoznaI, Y. (2014). Unconstitutional Constitutional Amendments: A Study of the Nature and Limits of Constitutional Amendment Powers [Tesis doctoral]. London School of Economics and Political Science.

Roznai, Y. y Jacobsohn, G. J. (2020). Constitutional Revolution. EE. UU.: Yale University Press.

Schmitt, C. (1952). Teoría de la Constitución. México: Editora Nacional.

- (2009). El Concepto de lo Político. Madrid: Alianza Editorial.

SiERra, H. (1998). La reforma de la Constitución. Bogotá: Universidad Externado de Colombia.

SiEYes, E. (2007). Escritos y discursos de la revolución. Madrid: Centro de estudios políticos y constitucionales.

Touraine, A. (2000). ¿Qué es la Democracia? (Trad. H. Pons). México: Fondo de Cultura Económica.

Valencia, H. (2010). Cartas de batalla: una crítica del constitucionalismo colombiano. Bogotá: Panamericana.

Waldron, J. (2005). Derecho y desacuerdo. Madrid: Editorial Marcial Pons. 


\title{
LA DOCTRINA DE LA SUSTITUCIÓN CONSTITUCIONAL EN COLOMBIA: UNA APROXIMACIÓN A LA JURISPRUDENCIA CONSTITUCIONAL
}

\author{
The doctrine of constitutional substitution in Colombia: \\ an approach to constitutional Jurisprudence
}

\section{Milton César Jiménez Ramírez}

Abogado, Universidad de Caldas

Especialista en Derecho Constitucional, Universidad Nacional de Colombia;

Magister en Derecho Público, Universidad Externado de Colombia;

Doctor en Derecho, Universidad Carlos III de Madrid; docente investigador

del Departamento de Jurídicas de la Universidad de Caldas

\section{Paulo Bernardo Arboleda Ramírez}

Abogado, Universidad de Medellín; Especialista en Derecho Público, Universidad Externado de Colombia; y, Magíster en Derecho, Universidad de Medellín; docente del Departamento de Jurídicas de la Universidad de Caldas

http://dx.doi.org/10.18543/ed-69(2)-2021pp123-148

\section{Copyright}

Estudios de Deusto es una revista de acceso abierto, lo que significa que es de libre acceso en su integridad. Se permite su lectura, la búsqueda, descarga, distribución y reutilización legal en cualquier tipo de soporte sólo para fines no comerciales, sin la previa autorización del editor o el autor, siempre que la obra original sea debidamente citada y cualquier cambio en el original esté claramente indicado

Estudios de Deusto is an Open Access journal which means that it is free for full access, reading, search, download, distribution, and lawful reuse in any medium only for non-commercial purposes, without prior permission from the Publisher or the author; provided the original work is properly cited and any changes to the original are clearly indicated. 